\title{
Can Wine and Moderate Alcohol Intake Work as Functional Food Nutraceuticals? A Tribute to Dr. Serge C. Renaud
}

\author{
Ram B. Singh $^{1}$, Fabien D. Meester ${ }^{1, *}$, Agnieszka Wilkzynska ${ }^{1}$, D.W. Wilson ${ }^{2}$, Domnique \\ Lanzmann $^{3}$, Maria Abramova ${ }^{4}$, Sergey A. Shastun ${ }^{4}$, Chibisov Sergey ${ }^{5}$, Pavel Khochunsky ${ }^{6}$, \\ Pratik S. Velangi ${ }^{7}$, Endrew Awori ${ }^{8}$, Akanshi Sharma ${ }^{9}$, Monika Jain ${ }^{9}$ and Harpal S. Buttar ${ }^{10}$ \\ ${ }^{I}$ The Tsim Tsoum Institute, Krakow, Poland \\ ${ }^{2}$ School of Medicine, Pharmacy and Health, Durham University, UK \\ ${ }^{3}$ Petithory, Praticien Hospitalier Hôpital Emile Roux, Geriatric Service, Limeil-Brévannes, France \\ ${ }^{4}$ Department of Normal Physiology, People's Friendship University of Russia, Moscow, Russia \\ ${ }^{5}$ Department of Pathology, People's Friendship University of Russia, Moscow, Russia \\ ${ }^{6}$ Medical student $\left(4^{\text {th }}\right.$ year $)$ at pfur \\ ${ }^{7}$ Medical student ( $2^{\text {nd }}$ year) at pfur, Moscow Russia \\ ${ }^{8}$ Medical student (2 $2^{\text {nd }}$ year) at pfur \\ ${ }^{9}$ Department of Food Science and Nutrition, Banasthali Vidyapith, Banasthali, India \\ ${ }^{10}$ University of Ottawa, School of Medicine, Ottawa, Canada
}

\begin{abstract}
Alcohol appears to be a double-edged sword because moderate alcohol intake is protective whereas drinking more than 10 drinks in a week appears to have adverse effects on morbidity and mortality. Recently, the exponential nature of the relation between average alcohol consumption and mortality has been demonstrated in Russia. This study revealed that substantial numbers of people report drinking three or more half-litre bottles of vodka per week. However, the exponential curves for dose-response relations between average volume of alcohol consumption and the mortality risk of various diseases is not fully explained. The variation in mortality may be due to presence of confounders such as physical activity, greater consumption of fish and salads which are rich sources of omega-3 fatty acids and polyphenolics. It is possible that patients with type 2 diabetes, moderate alcohol us-e, particularly wine consumption, is associated with reduced risks of cardiovascular events and all-cause mortality. Serge C. Renaud gave the definition of the French paradox and suggested that the inhibition of platelet reactivity by wine may be one explanation for protection from CAD in France. It is known that aging of alcohol also increases 1, 1-diphenyl-2-picrylhydrazyl radical scavenging activity and therefore moderate drinking of aged whisky and other alcoholic drinks in moderation may provide beneficial effects. Excess of alcohol intake causes decreases in vitamin B1, B6 and B12 as well as in folic acid, antioxidants vitamins A,E ,C and beta carotene, flavonoids, amino acids, coenzyme Q10, 1-carnitine, omega-3 fatty acids as well as in minerals magnesium, potassium, calcium, copper, zinc, chromium and selenium. Alcoholism also has a direct adverse effects on cell membrane, mitochondria and genes. Alcoholic cirrhosis, fatty liver, cardiomyopathy, hypertriglyceridemia, hyperuricemia, oxidative stress and inflammation are well known adverse effects of alcoholism. It also damages the brain causing dementia, depression and psychosis. However, moderate alcohol intake up to 10 drinks per week may have beneficial effects on the risk of all these problems. Moderate alcohol intake increases HDL-C, and decreases C-reactive proteins, IL-6, TNF-alpha, Lp (a), plasminogen activator inhibiter-1, insulin resistance which are risk markers of CVDs, type 2 diabetes and cancer. These beneficial effects are enhanced by omega-3 fatty acids and polyphenolics that are rich in Mediterranean style diets. Vodka and spirits can be made healthly if enriched with fish oil or alpha- linolenic acid (rich source of w-3) and cocoa (flavanol) which can repair this deficiency. It is like a cleaning drink for the all the organs of the body. If standard Vodka is $40 \%$ alcohol, then we need +/- 1-g DHA per 500-ml bottle.
\end{abstract}

Keywords: Death rate, ethanol, flavonoids, wine.

\section{INTRODUCTION}

There is apparent variation in alcohol consumption among authors of this article. While first 5 authors are

*Address correspondence to this author at the The Tsim Tsoum Institute, ul. Golebia 2, 31-007,Krakow, Poland; Tel/Fax: 48601780453;

E-mail: fdm@tsimtsoum.net modest drinkers and prefer wine, next two prefer vodka and one of us (SC) drinks unlimited amount of vodka resulting in to coronary artery disease and gastric ulcers. All the authors eat functional foods routinely and maintain a low omega6/omega-3 ratio of $<1: 5$ in the diet, but the quantity varies which is similar to population food consumption. There are huge variations in Russian mortality rates 1984-94 compared 
to causes of deaths in other countries [1,2]. Alcohol and cause-specific mortality in Russia in a retrospective casecontrol study of 48557 adult deaths revealed that alcoholism is a major cause of mortality [3]. In a more recent prospective observational study of 151000 adults on alcohol and mortality in Russia reported that alcohol associated deaths are increasing and increase in price of alcohol has only limited impact on consumption [4]. It is clear from the Russian studies, that heavy drinking has adverse effects which is particularly of greater magnitude from heavy episodic drinking $[1,3,4]$. The exponential nature of the relation between average alcohol consumption and mortality has been demonstrated in a recent study [4]. This study revealed that substantial numbers of people report drinking three or more half-litre bottles of vodka per week. However, the exponential curves for dose-response relations between average volume of alcohol consumption and the mortality risk of various diseases is not fully explained which may be due to presence of confounders. It seems that coexisting causes of death as well as health behavior patterns; functional food intake, spare time physical activity, no tobacco and psychosocial stress may be important cause of variability. Epidemiological studies indicate that moderate alcohol consumption has been associated with a reduced risk of mortality and coronary artery disease (CAD) [5-7]. The relationship between alcohol consumption and vascular complications and mortality in individuals with type 2 diabetes mellitus has been reported in a recent study showing beneficial effects of wine consumption [5]. The ADVANCE trial reported that during a median of 5 years of follow-up, 1,031 (9\%) patients died, 1,147 (10\%) experienced a cardiovascular event, and $1,136(10 \%)$ experienced a microvascular complication [5]. Compared with patients who reported no alcohol consumption, those who reported moderate consumption had fewer cardiovascular events (adjusted hazard ratio [aHR] 0.83 ; 95\% CI 0.72-0.95; $P=0.008$ ), less microvascular complications (aHR 0.85; 95\% CI $0.73-0.99 ; P=0.03$ ), and lower all-cause mortality (aHR 0.87; 96\% CI 0.75-1.00; $P=0.05$ ). The benefits were particularly evident in participants who drank predominantly wine (cardiovascular events aHR 0.78, 95\% CI 0.63$0.95, P=0.01$; all-cause mortality aHR $0.77,95 \%$ CI 0.62 $0.95, P=0.02)$. Those patients, who reported heavy consumption had dose-dependent higher risks of cardiovascular events and all-cause mortality, compared with patients who reported no alcohol consumption, It is possible that patients with type 2 diabetes, moderate alcohol use, particularly wine consumption, is associated with reduced risks of cardiovascular events and all-cause mortality. In a meta-analysis, the association between moderate alcohol consumption and reduced mortality risk appears to be beyond question [10]. It is possible that strong evidence for underlying biological mechanisms warranted re-focusing research towards investigating how best to communicate health benefits to the general population $[10,11]$. This analysis reviewed all of the 67 studies which generated the 84 articles in the Ronksley meta-analysis. All but two suffered from at least one of six serious methodological problems. Cardiovascular risk factors and confounders among non-drinking and moderate drinking population have been reported from United States showing several confounders [12]. Global alcohol exposure estimates by country, territory and region for 2005- a contribution to the comparative risk assessment for the 2010, in the Global Burden of Disease Study revealed that alcohol intake has become a major public health problem [13]. In USA, over $51 \%$ people are regular drinkers, over the age of 18 years but in South East Asia, alcohol intake appears to be common among $10-20 \%$ of subjects mainly among males as social drinkers. Since regular intake of alcohol may be associated with greater risk of hepatic complications and certain cancers, it may be difficult to make firm recommendations for alcohol consumption among patients with type 2 diabetes [14].

\section{WINE AS FUNCTIONAL FOOD NUTRACEUTICAL}

Serge C. Renaud gave the definition of the French paradox and suggested that the inhibition of platelet reactivity by wine may be one explanation for protection from CAD in France [8]. The French paradox is the observation of low CAD death rates despite high intake of dietary cholesterol and saturated fat. The French paradox concept was formulated by French epidemiologists in the 1980s because British, Swedish, Finnish and French eat the same amount of fat but French have lower rate of cardiovascular diseases (CVDs) [15]. France is a country known for low CAD incidence and mortality compared to Britain, Finland and Sweden. The mean energy supplied by fat was 38\% in Belfast and 36\% in Toulouse in 1985-86.' and recently, in 1995-97, the percentage of energy from fat was $39 \%$ in Toulouse according to a representative population survey in France. Differences in coronary mortality can be explained by differences in cholesterol and saturated fat intakes in 40 countries but not in France and Finland, which may be a paradox [9]. The Russian paradox also appears to be similar which needs further cohort studies. The Indian paradox is that rural population have lower fat intake (15\% en $v s$ 25\%) lower prevalence of CAD ( 3.0 vs $9.0 \%)$ compared to urban subjects [16]. However, Indian immigrants to industrialized countries, have much greater prevalence $(14 \%)$ and $30 \%$ greater mortality due to CAD, although, the total fat intake is lower compared to Caucasians (35.0 vs 40\% en) [16].

France and Finland have similar intakes of cholesterol and saturated fat, but consumption of vegetables and vegetable oil containing monounsaturated and polyunsaturated fatty acids is greater in France than in Finland [15]. In Russia, vegetables and salads as well as fish and its eggs are quite popular which are functional foods and are virtues of Russian diets. It is known that aging of alcohol also increases 1, 1-diphenyl-2-picrylhydrazyl radical scavenging activity and therefore moderate drinking of aged whisky and other alcoholic drinks in moderation may provide beneficial effects $[8,17]$. Further studies are needed in Russia and other countries, to find out, how many subjects consuming red or white wine and how often in a week, have significant beneficial effects, because wine appears to be a functional food nutraceutical if taken in moderation. It would also be interesting to know the effect of moderate alcohol verses drinking more than 10 drinks per week, because moderate drinking appears to be protective against cardiovascular diseases (CVDs). Epidemiological studies indicate that consumption of alcohol at the level of intake in 
France (20-30 g per day) can reduce risk of CAD by at least $40 \%$ but it is more for wines. Inhibition of platelet reactivity by wine (alcohol) may be one explanation for protection from CAD in France, since pilot studies have shown that platelet reactivity is lower in France than in Scotland. In an earlier study on cause specific mortality from Russia, alcohol-attributable mortality varied by year [2]. In recent years, alcohol was a cause of more than half of all Russian deaths at ages 15-54 years [3]. Alcohol accounted for most of the large fluctuations in Russian mortality, and alcohol and tobacco accounted for the large difference in adult mortality between Russia and Western Europe [2, 3]. It is not clear that how common was the health behavior pattern among Russians in of these studies [2, 3]. Effects of resveratrol (which is rich in wine), on cerebral blood flow variables and cognitive performance in humans in a doubleblind, placebo-controlled, crossover investigation reported beneficial outcome indicating that wine can benefit both heart and the brain [18]. It would be interesting to know how common are wine consumption, prudent dietary patterns; (cocoa, probiotics, omega-3 fatty acids and polyphenolics) moderate physical activity, no tobacco and active prayer to relieve mental stress which may be important confounders for protection against CVDs [18-22].

Epidemiological studies indicate that increased intake of alcohol more than 10 drinks per week may be associated with increased risk of heart attack, stroke, hypertension, diabetes mellitus and cancers as well as accidents [2-5]. Greater the intake of alcohol the higher the risk of these chronic diseases and deaths due to these problems. Excess of alcohol intake causes decrease in vitamin $\mathrm{B}_{1}, \mathrm{~B}_{6}$ and $\mathrm{B}_{12}$ as well as in folic acid, antioxidants vitamins $\mathrm{A}, \mathrm{E}, \mathrm{C}$ and beta carotene, flavonoids, amino acids, $\mathrm{CoQ}_{10}, 1$-carnitine, omega3 fatty acids as well as in minerals $\mathrm{Mg}, \mathrm{K}, \mathrm{Ca}, \mathrm{Cr}, \mathrm{Zn}, \mathrm{Se}$. Alcoholism also has a direct adverse effects on cell membrane, mitochondria and genes. Alcoholic cirrhosis, fatty liver, cardiomyopathy, hypertriglyceridemia, hyperuricemia, oxidative stress and inflammation are well known adverse effects of alcoholism [2-5]. It also damages the brain causing dementia, depression and psychosis. However, moderate alcohol intake up to 10 drinks per week may have beneficial effects on the risk of all these problems. Moderate alcohol intake increases HDL-C, and decreases CRP, IL-6, TNF-alpha, Lp (a), Plasminogen activator inhibiter-1, insulin resistance. These beneficial effects are enhanced by omega-3 fatty acids, whereas eating excess of omega- 6 fatty acids may decrease these beneficial effects of both the agents [2-7].

Western diet rich in omega-6 fat (sun flower oil, corn oil, saiflower oil, soya bean oil), trans fat, saturated fat and refined carbohydrates and low in w-3 fatty acids, vitamins, antioxidants and amino acids is known to contribute to all the above diseases. Therefore, western diet in conjunction with alcoholism doubles the risk of deaths due to chronic diseases. If the diet is rich in all these nutrients, these chronic diseases can be decreased. However, it is not possible for general population to eat adequate fruits, vegetables, legumes and nuts (walnuts rich in w-3) and olive oil and rape seed oil (w-3 rich) which are rich sources of above nutrients. There is need to add omega- 3 fatty acids and cocoa in the alcohol to decrease these complications and deaths because it seems to be central in the above mechanism. Alcohol drains some DHA (w-3 fat) and flavonoids and other endogenous antioxidants from the cells of the brain, heart, arteries, liver, beta cells of pancreas, stomach, duodenum and ileum and breast in females, predisposing these organs to above chronic diseases. Vodka can be made healthful if enriched with fish oil or alpha-linolenic acid (rich source of w-3) and cocoa which can repair this deficiency. It is like a cleaning drink for the all the organs of the body. If standard Vodka is $40 \%$ alcohol, then we need +/- 1-g DHA per 500-ml bottle. Eating designer foods with low w-6/w-3 ratio of $1: 1$ in conjunction with cocoa flavones or other flavonoids, may also decrease the adverse effects of alcoholism and may enhance the beneficial effects of moderate alcohol consumption, which may be a virtue of Russia [17-23]. Recent studies indicate that the association of moderate alcohol intake and cancer may be positive and beneficial effects reported by some authors may be due to under-reporting [24-26].

In a cohort study involving 36583 healthy middle aged men, mortality from all causes and from specific causes during a 13-21-y follow-up was recorded [27]. In a Cox model adjusted for 6 confounding variables, moderate wine drinkers (those who consumed $<60 \mathrm{~g}$ alcohol/d and no beer) with systolic blood pressure of 158,139 , or $116 \mathrm{mmHg}$ had significantly lower risks of death from all causes by $23 \%$, $27 \%$, and $37 \%$, respectively, than did abstainers. Moderate wine drinkers were protected from all-cause mortality despite highest blood pressures. No significant reduction in all-cause mortality in relation to SBP was observed in other drinkers (those who consumed $\geq 60 \mathrm{~g}$ alcohol/d or who consumed beer and wine). A moderate intake of wine was associated with a lower risk of mortality from all causes in persons with hypertension.

However the relation of alcohol and cardiovascular and brain health indicate that the dose makes the poison or the remedy causing antiplatelet effect which is a remedy or oxidative stress which is a risk marker of athero-thrombosis as well as brain dysfunction [28, 29]. It seems that cell membranes of the neurons as well as cardiomyocyte and vascular cells are protected by omega 3 fatty acids and flavonoids against damaging effects of alcohol [29]. In a more recent study, the antioxidant flavonoid found in red wine, chocolate and grapes are not associated with improved health among participants ( 783 subjects 65 years and above) in the Ageing in the Chianti Region Study from 1998 to 2009 in two regions in Italian villages [30]. During a follow up of 9 years, $34.3 \%(\mathrm{n}=268)$; of 639 subjects free of CVDs at entry, 27.2\% ( $\mathrm{n}=174)$ developed CVDs and 734 subjects who were free of cancer at the entry, $4.6 \%(n=34)$ developed cancer. Urine resveratrol metabolite levels were not associated with deaths, inflammation, CVDs or cancer thus no beneficial effects on longevity noted. It seems that resveratrol metabolites are not suitable biomarkers to correlate CVDs and cancer with wine drinking.

In brief, wine in general, red wine in particular, appears to be a functional food nutraceutical which may be beneficial in the prevention of CVDs and type 2 diabetes, whereas excess of alcohol intake may be injurious to health. Adding omega-3 fatty acids and cocoa/grapes flavonoids to vodka or other alcohol may be protective against adverse effects of 
greater consumption of alcohol but more studies are needed to prove this hypothesis. We would be failing in our duty if we do not acknowledge the proposal of Serge C. Renaud about flavonoids and their effects on platelet reactivity, in providing this benefit [8].

Prof Dr. Serge C. Renaud (born November 21, 1927 and died October 28, 2012).

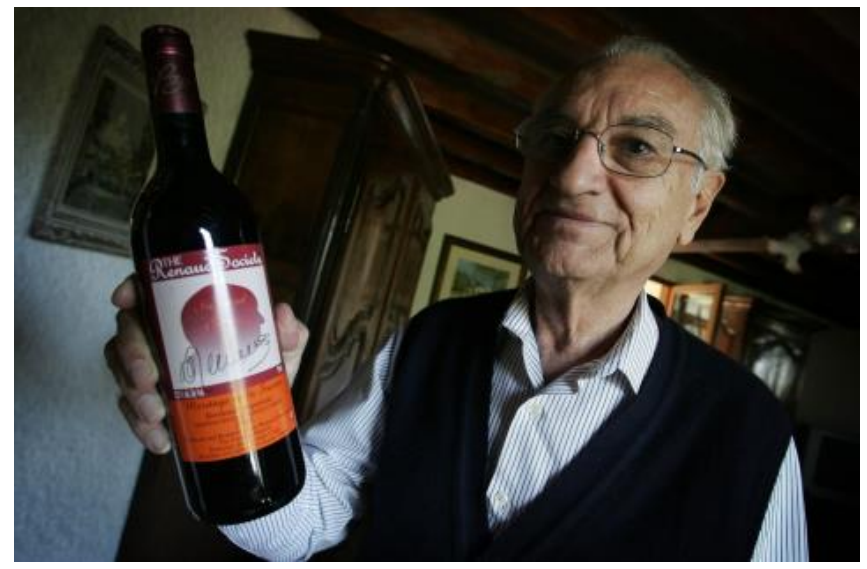

Fig. (1). Serge C. Renaud with a bottle of wine.

Serge C. Renaud became an overnight celebrity in 1991 when he appeared on the American CBS documentary program 60 Minutes, which was investigating why France had only a third of the American rate of cardiovascular disease, despite a diet equally rich in fat. Renaud argued that the two or three glasses of red wine most French people consumed every day with their meals was a significant reason for their better health. In 1992 American sales of red table wine increased by nearly 40 per cent and stayed strong over subsequent years.

Serge C. Renaud was born on November 211927 at Cartelègue, in the Haute Gironne, where his grandfather had a vineyard in Entre-Deux-Mers. After reading Medicine at Bordeaux University he moved to Montreal, Canada, where he took a doctorate in cardiovascular disease, and later to Boston.

In 1973 he returned to France as a director of public medical research at the French National Institute of Health and Medical Research in Lyon, where he carried out most of his research.

Following his 60 Minutes interview the US Bureau of Alcohol, Tobacco and Firearms challenged Renaud to show figures to back up his claims about red wine; and in an article in The Lancet in 1992 he drew on epidemiological research and data of his own to claim that 20 to 30 grams of alcohol a day (about two to three standard glasses of wine) could reduce the risk of dying from a heart attack by 40 per cent. Wine protects the heart, he maintained, mainly by acting on platelets in the blood to prevent clotting.

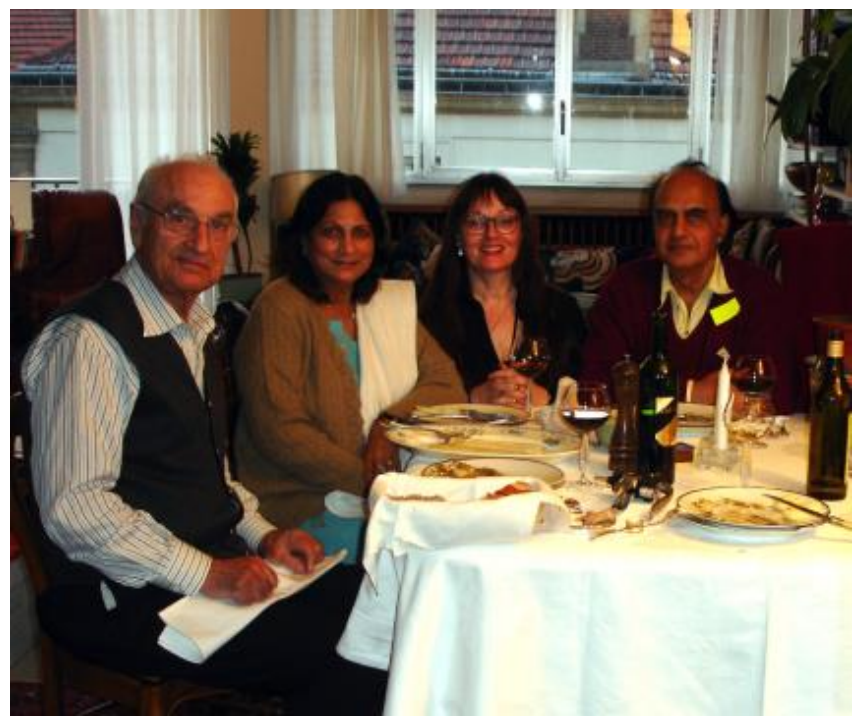

Fig. (2). Serge C. Renaud along with Sushav Singh, Petithory Lanzman and R.B. Singh.

Renaud went on to carry out a study of 34,000 middleaged men living in eastern France which supported the "French Paradox" and showed that, as well as protecting against heart disease, moderate consumption of red wine also protects against most cancers. In a study he reported a 30 per cent lower than expected overall risk of death in men who drank two or three glasses of wine a day. In another study with colleagues, he showed a 70 per cent lower risk of fatal heart attack in people adopting a "Cretan" diet which replaced butter with margarine and emphasised more bread, less meat, and included fruit and vegetables containing vitamin $\mathrm{C}$. The study concluded that the lower incidence of heart failure in Crete, compared with mainland Greece or Italy, was due to the Cretans' high consumption of olive oil, nuts and vegetables. We; Dr. Sushav Singh, Dr. Petithory Lanzmann and R.B. Singh also had pleasure of having wine with Dr. Renaud.

Renaud was appointed to the Légion d'honneur in 2005. In America an academy of cardiologists was named in his

\section{Table 1. Clinical characteristics of French Paradox [Modified from Ref 15].}

1. There is a greater intake of dietary cholesterol and saturated fat but low CAD death rates indicating, the French paradox

2. Variability of CAD rates and coronary risk factors is the rule, and low CAD rates are observed in southern or Mediterranean European countries and rural population of India eating low fat diet [16].

3. Classical risk factors do not embrace the totality of CAD risk, particularly in France and in other southern European countries and in South Asians

4. Drinking of wine and attitudes to food could lower CAD incidence and mortality.

5. The French paradox ascertains that primary prevention, based on an optimal diet rich in fruit and vegetables, nuts, regular physical exercise, and no tobacco, is worthwhile.

6. The French paradox is an incentive for more research in countries with low CAD incidence and probably more protective against conventional CAD risk factors. 
honour.

Serge C. Renaud is survived by a daughter.

\section{CONFLICT OF INTEREST}

Conflict of interest has not been declared by the authors.

\section{ACKNOWLEDGEMENTS}

Acknowledgements are due to the International College of Nutrition to provide logistic support to write this article.

\section{REFERENCES}

[1] Singh RB, Singh S, Singh V, Kulshresth SK, Mechirova V, Pella D. Association of increased mortality with underweight, overweight and obesity among urban descents in North India dying due to various causes. World Heart J 2008; 1: 341-7.

[2] Leon DA, Chenet L, Shkolnikov V, et al. Huge variation in Russian mortality rates 1984-94: artefact, alcohol, or what?. Lancet 1997; 350: 383-8.

[3] Zaridze D, Brennan P, Boreham J, et al. Alcohol and cause-specific mortality in Russia: a retrospective case-control study of 48557 adult deaths. Lancet 2009; 373: 2201-14.

[4] Zaridze D, Lewington S, Boroda A, et al. Alcohol and mortality in Russia: prospective observational study of 151000 adults. Lancet 2014. Published online Jan 31. http://dx.doi.org/10.1016/ S0140-6736(13)62247-3.

[5] Blomster JI, Zoungas S, Chalmers J, et al. The relationship between alcohol consumption and vascular complica-tions and mortality in individuals with type 2 diabetes mellitus. Diabetes Care. Published online before print. February 27, 2014, doi: $10.2337 / \mathrm{dc} 13-2727$

[6] Friedman LA, Kimball AW. Coronary heart disease mortality and alcohol consumption in Framingham. Am J Epidemiol 1986; 124: 481-9.

[7] Keef JH, Bybee KA, Lavie CJ. Alcohol and cardiovascular health: the razor-sharp double edged sword. J Am Coll Cardiol 2007; 50: 1009-14.

[8] Renaud S, de Lorgeril M. Wine, alcohol, platelets and the French paradox for coronary heart disease. Lancet 1992; 339: 1523-26.

[9] Artaud-Wild SM, Connor SL, Sexton G, et al. Differences in coronary mortality can be explained by differences in cholesterol and saturated fat intakes in 40 countries but not in France and Finland. A paradox. Circulation 1993; 88: 2771-9.

[10] Ronksley PE, Brien SE, Turner BJ, Mukamal KJ, Ghali WA. Association of alcohol consumption with selected cardiovascular disease outcomes: a systematic review and meta-analysis. BMJ 2011; 342: d671. BMJ2011;342 doi: http://dx.doi.org/10.1136/ bmj.d671(Published 22 February 2011)

[11] Brien S, Ronksley P, Turner T, Mukamal K, Ghali W. Effect of alcohol consumption on biological markers associated with risk of coronary heart disease: systematic review and meta-analysis of interventional studies. Bri Med J 2011; 342: d636.
[12] Naimi T, Brown D, Brewer R, et al. Cardiovascular risk factors and confounders among nondrinking and moderate drinking U.S. adults. Am J Prev Med 2005; 28: 369-73.

[13] Shield KD, Ryleu M, Gmel G, Kehoechan TA, Rehm I. Global alcohol exposure estimates by country, territory and region for 2005- a contribution to the comparative risk assessment for the 2010, Global Burden of Disease Study. Addiction 2013; 108: 91222.

[14] Nochols M, Scarborough P, Allender S, Rayner M. What is the optimal level of population alcohol consumption for chronic disease prevention in England? Modelling the impact of changes in average consumption levels. BMJ Open 2012; 2: e000957.

[15] Ferrieres J. The French paradox: lessons for other countries. Heart 2004; 90: 107-11.

[16] Singh RB, Niaz MA. Coronary risk factors in Indians. Lancet 1996; 346: 778-9.

[17] Aoshima H, Tsunoue H, Koda H, Kiso Y. Aging of whiskey increases 1, 1-diphenyl-2-picrylhydrazyl radical scavenging activity. J Agri Food Chem 2004; 52(16): 5240-44.

[18] Kennedy DO, Wightman EL, et al. Effects of resveratrol on cerebral blood flow variables and cognitive performance in humans: a double-blind, placebo-controlled, crossover investigation," Am J Clin Nutr, 2010 March 31;Published before print.

[19] Hristova K, Nakaoka T, Otsuka K, et al. Perspectives on chocolate consumption and risk of cardiovascular diseases and cognitive function. Open Nutra J 2012; 5: 207-12.

[20] Barraud D, Bollaert PE, Gibot S. Impact of the administration of probiotics on mortality in critically ill adult patients: A metaanalysis of randomized controlled trials. Chest 2013; 143: 646-55.

[21] PREDIMED Study Investigators. Primary prevention of cardiovascular disease with a Mediterranean diet. N Engl J Med 2013; February 25, 2013, DOI: 10.1056/NEJMoa1200303

[22] Singh RB, Dubnov G, Niaz MA, et al. Effect of an IndoMediterranean diet on progression of coronary disease in high risk patients: a randomized single blind trial. Lancet 2002; 360: 145561.

[23] Horton R. The virtues of Russia. Lancet 2014; 383(9928): 1532.

[24] Rehm J, Shield K. Alcohol consumption. In: Stewart BW, Wild $\mathrm{CB}$, Eds. World Cancer Report. Lyon, France: International Agency for Research on Cancer (2014).

[25] Bagnardi V, Rota M, Botteri E, et al. Light alcohol drinking and cancer: a meta-analysis. Ann Oncol 2013; 24: 301-8.

[26] Klatsky AL, Udaltsova N, Li Y, Baer D, Nicole Tran H, Friedman GD. Moderate alcohol intake and cancer: the role of underreporting. Cancer Causes Control. 2014 Apr 2. [Epub ahead of print].

[27] Renaud SC, Guéguen R, Conard P, Lanzmann-Petithory D, Orgogozo JM, Henry O. Moderate wine drinkers have lower hypertension-related mortality: a prospective cohort study in French men Am J Clin Nutr 2004; 80(3): 621-5

[28] O'Keefe JH, Bhatti SK, Bajwa A, DiNicolantonio JJ, Lavie CJ. Alcohol and cardiovascular health: the dose makes the poison or the remedy. Mayo Clin Proc 2014; 89: 382-93.

[29] http://www.tsimtsoum.net/publicevents/11th\%20HEM\%20 \%20Editorial\%20TsimTsoum.pdf

[30] Semba RB. Resveratrol in red wine, chocolates, grapes, not associated with improved health. JAMA Intern Med, Published online May 12, 2014.doi:10.1001/jamainternmed. 2014.1582

Received: September 05, 2014

Revised: September 16, 2014

Accepted: September 17, 2014

(C) Singh et al.; Licensee Bentham Open.

This is an open access article licensed under the terms of the Creative Commons Attribution Non-Commercial License (http://creativecommons.org/licenses/by-nc/3.0/) which permits unrestricted, non-commercial use, distribution and reproduction in any medium, provided the work is properly cited. 